\title{
P 098 THE CHALLENGES OF PROVIDING A CARERS' ASSESSMENT FOR PALLIATIVE CARE PATIENTS IN A TERTIARY CANCER CENTRE
}

Julian Hampton - Matthews, Alison Coackley, Agnes Noble, Ann Griffiths, Margaret Foulkes, Susan Howarth. Clatterbridge Cancer Centre, Bebington, England

10.1136/bmjspcare-2014-000654.139

Background The author works in a tertiary centre in the UK, caring for over 7,000 new patients per year. Carers play a central role in providing support to patients. However, many carers do not experience a cohesive integrated system of social support. Optimal input for carers will depend on a comprehensive assessment of the situation and their needs.

Aim To develop an assessment tool that can be used by all health care professionals to assess the carers' needs and provide appropriate intervention to support the carers.

Method A multi-professional group was set up to establish the baseline needs of carers. The assessment and documentation of carers' concerns and needs was evaluated using the documentation recorded on the Trust's electronic system. The Cancer Centre joined a major research project untaken by a local university and another NHS Trust to develop an assessment tool for carers who care for palliative patients. Staff took part in an on-line questionnaire to prioritise the issues they feel result in an increase in carer stress which could affect their ability to provide care.

Results The research showed that carers' concerns and needs were not being formally assessed. From the information collated a draft Carers' Needs Assessment Thermometer was produced and piloted to carers. The evaluation from carers and health care professionals who have used this tool will help finalise the tool which can be used for carers.

Recommendations Carers' Needs Assessment Thermometer will be used at the Cancer Centre to assess the needs of carers supporting palliative care patients. The tool will be used in conjunction with a carers' directory which was also developed at the Cancer Centre, which gives information on advocacy support, carers' allowance, national support organisations and supported is available in the carer's area. 